\title{
Outcomes of TB/HIV co-infected patients presenting with antituberculosis drug-induced liver injury
}

\author{
S Naidoo, ${ }^{1} \mathrm{MB}$ ChB; D Evans, ${ }^{2}$ DBiomed; E Jong, ${ }^{3} \mathrm{MD}$, PhD; K Mellet ${ }^{3} \mathrm{MB}$ ChB, Dip HIV Man; R Berhanu, ${ }^{4}$ MD, DTM\&H, Dip HIV Man \\ ${ }^{1}$ Helen Joseph Hospital, Johannesburg, South Africa \\ ${ }^{2}$ Health Economics and Epidemiology Research Office, Department of Internal Medicine, School of Clinical Medicine, \\ Faculty of Health Sciences, University of the Witwatersrand, Johannesburg, South Africa \\ ${ }^{3}$ Clinical HIV Research Unit, Department of Internal Medicine, School of Clinical Medicine, Faculty of Health Sciences, \\ University of the Witwatersrand, Johannesburg, South Africa \\ ${ }^{4}$ Right to Care, Helen Joseph Hospital, Johannesburg, South Africa
}

Corresponding author: S Naidoo (sashelin@gmail.com)

\begin{abstract}
Background. South Africa has a significant burden of tuberculosis (TB). Anti-TB drug-induced liver injury (TB DILI) is one of the most serious adverse events that can arise from TB treatment (TBT). There are limited data on TB DILI among HIV-infected patients and those on antiretroviral therapy (ART).

Objective. To describe characteristics of HIV-infected patients presenting with TB DILI and the proportion reintroduced on standard or modified TBT after DILI.

Methods. This was a retrospective study of TB/HIV co-infected patients with DILI between 1 July 2009 and 30 September 2012. The primary focus of interest was HIV-infected patients with TB DILI on ART (ART/TB DILI) v. not on ART (TB DILI).

Results. A total of 94 patients were included, 41 with TB DILI and 53 with ART/TB DILI. Compared with patients with TB DILI, patients with ART/TB DILI were more likely to present with symptomatic DILI $(71.2 \%$ v. $51.2 \% ; p=0.03)$ and had a lower median alanine aminotransferase level at diagnosis $(89 \mathrm{IU} / \mathrm{L}$ v. $118 \mathrm{IU} / \mathrm{L} ; p=0.008)$, a lower rate of ALT decline $(-23 \mathrm{IU} / \mathrm{L} \mathrm{v} .-76 \mathrm{IU} / \mathrm{L} ; p=0.047)$ and longer duration of TBT at DILI diagnosis (53 days v. 11 days; $p<0.001$ ). In $71.8 \%$ of patients, standard TBT was reintroduced. More patients with ART/TB DILI than TB DILI required modified TBT (37.2\% v.17.1\%; $p=0.05$; crude odds ratio 2.17 ; $95 \%$ confidence interval 0.95 - 4.96 ). The rate of death/loss to follow-up was higher in the ART/TB DILI group (18.9\% v. 14.5\%).

Conclusion. A significant number of TB/HIV co-infected patients were not able to tolerate standard TBT. Furthermore, ART appears to complicate TBT, with relatively fewer patients reintroduced on standard TBT.

S Afr Med J 2015;105(5):393-396. DOI:10.7196/SAMJ.8217
\end{abstract}

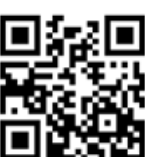

Tuberculosis (TB) and HIV are inextricably linked; not only are HIV-infected people up to 30 times more likely to develop active TB in their lifetimes, but they also have a higher risk of dying from TB than those who are not infected with HIV. ${ }^{[1-3]}$ This dual-disease phenomenon has significant implications for South Africa (SA), which has the highest number of TB/HIV co-infected patients in the world. ${ }^{[1-3]}$

Anti-TB drug-induced liver injury (TB DILI) is one of the most serious adverse consequences of TB treatment (TBT), with a significant impact on TBT outcomes. A proportion of patients who experience TB DILI will require modification of the highly effective standard regimen, which relegates them to suboptimal regimens and exposes them to poor treatment outcomes with increased morbidity and mortality. ${ }^{[4-6]}$ Furthermore, TB DILI impacts negatively on health resources as it increases costs and utilisation of health services. ${ }^{[7]}$ Examples of this include increased nurse and physician visits, and the more intensive testing and monitoring that become necessary. The consequences of TB DILI are experienced most prominently by the developing world, including SA, where resources are limited and the TB disease burden is high.

The effect of antiretroviral therapy (ART) on TB DILI is not clear. A study conducted in both hospitalised patients and outpatients in Jimma, Ethiopia, found that the effect of ART is not significantly associated with outcome or adverse effects in TB/HIV co-infected patients ${ }^{[8]}$ However, a study conducted in hospitalised patients in Cape Town, SA, demonstrated a higher in-hospital and 3-month mortality of $35 \%$ in the ART/TB DILI group compared with $27 \%$ in patients with TB DILI alone. This was significantly higher than the
$8 \%$ mortality at 6 months among the general population of patients with TB/HIV co-infection treated at the hospital. ${ }^{[9]}$

The aim of this article is to describe patient characteristics of an SA adult HIV-infected population presenting with TB DILI, determine the factors that impact on the reintroduction of a standard or modified TBT regimen, and compare TB DILI with ART/TB DILI.

\section{Methods}

\section{Study site and population}

This study was a retrospective folder review of adult HIV-infected TB DILI patients presenting to a hospital-based TB clinic in Johannesburg, SA, between 1 July 2009 and 30 September 2012.

Included were all adult (age $\geq 18$ years) HIV-infected TB DILI patients receiving standard first-line TBT for confirmed or probable active TB. Standard first-line TBT is a fixed-dose combination of rifampicin (RIF), isoniazid (INH), pyrazinamide (PZA) and ethambutol (ETH) during the intensive phase of treatment, and RIF and INH during the continuation phase of treatment. The diagnosis of TB was considered confirmed when acid-fast bacilli could be demonstrated by microscopy, when Mycobacterium tuberculosis (MTB) was detected by a molecular amplification technique (Cepheid GeneXpert MTB/RIF, USA; Genotype MTBDR Hain Lifescience, GmbH, Germany), or when a tissue biopsy sample demonstrated histopathological changes in keeping with TB. In the absence of such confirmation, the diagnosis was considered probable when clinical and/or radiological signs of TB infection were associated with a definitive response to treatment after initiating TBT. Patients were excluded if they had resistance to RIF or INH on lineprobe assay or phenotypic drug susceptibility testing, if neither clinic nor 
hospital medical files were available for review, or if they presented at the TB clinic outside the study period.

A diagnosis of TB DILI was defined as: (i) alanine aminotransferase (ALT) level more than three times the upper limit of normal (ULN), associated with symptoms of acute hepatic injury (abdominal pain, nausea, vomiting, anorexia or jaundice); (ii) ALT level more than five times the ULN in the absence of any symptoms; or (iii) total bilirubin (TBR) more than two times the ULN. The ULN for ALT and TBR as per the SA National Health Laboratory Service reference range was $40 \mathrm{IU} / \mathrm{L}$ and $21 \mathrm{IU} / \mathrm{L}$, respectively.

\section{Study procedure}

Information obtained from the patients' medical records included date of birth, gender, site of TB, basis of diagnosis, phase of treatment, symptoms, comorbid conditions, hepatotoxin ingestion (including prescription medication, traditional or herbal remedies, and alcohol), HIV status, CD4 count, ART details, serial liver function tests (LFTs), viral hepatitis studies, abdominal ultrasound findings and TB drug reintroduction details.

Pattern of liver injury was based on the predominant pattern of liver enzyme elevation. An LFT that demonstrated a predominant elevation of TBR (v. ALT) was considered cholestatic, primarily elevated ALT (v. TBR) was considered transaminitis, and nondiscernible cases were considered mixed.

\section{Study definitions}

The exposure was defined as HIV-infected patients on ART presenting with TB DILI (ART/TB DILI) v. not on ART (TB DILI).

The main outcome of the study was the proportion of patients reintroduced to a standard or modified treatment regimen after a DILI diagnosis. A standard treatment regimen was defined as the successful reintroduction of a regimen containing RIF and $\mathrm{INH}$, whereas a modified treatment regimen was defined as a case where worsening clinical or biochemical parameters precluded the reintroduction of both RIF and INH. Secondary outcomes included retention in care and rate of decline in LFT (TBR, ALT, gamma-glutamyl transferase, albumin) after TB DILI diagnosis. Loss to follow-up was defined as more than 180 days since the last clinic visit.

\section{Statistical analysis}

Patient demographics and clinical characteristics of the cohort were summarised using descriptive statistics. Groups (TB DILI v. ART/ TB DILI) were compared using Student's $t$-test for parametric or normally distributed data, the Kruskal-Wallis test for non-parametric data or data that are not normally distributed for continuous variables, and the $\chi^{2}$ test for proportions. The association between potential risk factors and reintroduction on a modified treatment regimen was performed using logistic regression to estimate the odds ratio (OR) with 95\% confidence intervals (CIs). Data were collected and imported into SAS version 9.3 (SAS Institute Inc., USA) for analysis.

\section{Ethics}

The study was approved by the Human Research Ethics Committee of the University of the Witwatersrand, Johannesburg (Certificate number: M120750).

\section{Results}

A total of 94 patients with TB DILI were identified from TB clinic records. Table 1 shows the baseline characteristics of the study

\section{Table 1. Characteristics of patients with TB DILI and ART/TB DILI}

\begin{tabular}{llll}
\hline & $\begin{array}{l}\text { All } \\
(\boldsymbol{N}=\mathbf{9 4})\end{array}$ & $\begin{array}{l}\text { TB DILI } \\
(\boldsymbol{n}=\mathbf{4 1})\end{array}$ & $\begin{array}{l}\text { ART/TB-DILI } \\
(\boldsymbol{n}=\mathbf{5 3})\end{array}$ \\
\hline $\begin{array}{l}\text { Age }(\text { years), median (IQR) } \\
\text { Gender male, } n(\%)\end{array}$ & $40(33.7-44.9)$ & $39(32.9-44.7)$ & $39(34.5-44.7)$ \\
Site of TB, $n(\%)$ & $45(47.9)$ & $20(48.8)$ & $25(47.2)$ \\
Pulmonary & $18(19.1)$ & $6(14.6)$ & $12(22.6)$ \\
Extrapulmonary & $76(80.9)$ & $35(85.4)$ & $41(77.4)$ \\
CD4 (cells/ $\mu \mathrm{L})$, median $(\mathrm{IQR})$ & $77(31-160)$ & $79(35-107)$ & $76(31-187)$ \\
$<50, n(\%)$ & $38(40.4)$ & $16(39.0)$ & $22(41.5)$ \\
$51-100, n(\%)$ & $22(23.4)$ & $13(31.7)$ & $9(17.0)$ \\
$101-250, n(\%)$ & $24(25.5)$ & $10(24.4)$ & $14(26.4)$ \\
$>250, n(\%)$ & $10(10.6)$ & $2(4.9)$ & $8(15.1)$
\end{tabular}

Phase of TBT at DILI

diagnosis, $n$ (\%)

$\begin{array}{llll}\text { Intensive phase } & 83(88.3) & 40(97.6) & 43(81.1) \\ \text { Continuation phase } & 8(8.5) & 1(2.4) & 7(13.2) \\ \text { Unknown } & 3(3.2) & 0(0) & 3(5.7)\end{array}$

Symptomatic DILI, $n(\%) \quad 59(62.8) \quad 21(51.2) \quad 38(71.2)$

Duration of TBT at DILI $\quad 31.0(8.0-62.0) \quad 11.0(4.5-30.5) \quad 53.0(28.0-70.0)$

diagnosis (days), median (IQR)

Duration between stopping

TBT and starting re-challenge (days), median (IQR)

Pattern of liver injury, $n$ (\%)

$\begin{array}{llll}\text { Cholestatic } & 39(41.5) & 17(41.5) & 22(41.5) \\ \text { Transaminitis } & 18(19.1) & 7(17.0) & 11(20.8) \\ \text { Mixed } & 37(39.4) & 17(41.5) & 20(37.7)\end{array}$

Duration of ART at DILI

diagnosis (days), median (IQR)

ART regimen, $n$ (\%)
NRTI/NNRTI-based

regimen

PI-containing regimen

Unknown

TBR (IU/L), median (IQR)

ALT (IU/L), median (IQR)

Albumin (g/L), median (IQR)

New treatment regimen, $n(\%)$

Standard

Modified
$47 / 53(88.68)$

$4 / 53(7.55)$

$2 / 53(3.77)$

$50.0(24.0-89.0) \quad 46.0(14.5-93.5) \quad 57.0(26.0-84.0)$

$101.5(58.0$ - 202.0) $\quad 118.0(74.5-241.0) \quad 89(55.0-202.0)$

$18.0(15.0-22.0) \quad 18.0(15.0-21.5) \quad 18.5(16.0-24.0)$
$29 / 35(82.9)$ 
population. The average patient age was 40 years (interquartile range (IQR) 33.7 - 44.9). The study included 45 males (47.9\%) and 49 females (52.1\%). Eighty-three cases of TB (88.3\%) were considered to be confirmed diagnoses, and of these patients $80.9 \%$ had extrapulmonary TB. The median CD4 count at DILI diagnosis was 77 cells/ $\mu \mathrm{L}$ (IQR 31 - 160).

In 83 cases ( $88.3 \%$ ) patients presented with $\mathrm{TB}$ DILI while on the intensive phase of treatment On average patients experienced symptoms for 6.5 days (IQR 3.0 - 10.0) before seeking medical attention. However, only 59 patients (62.8\%) had symptoms of TB DILI. The most common symptoms were jaundice, vomiting, abdominal pain and anorexia. Abdominal ultrasound was performed on 76 patients $(80.8 \%)$, of whom the majority had one or more features suggesting abdominal TB. Patients had received TB treatment for an average of 31.0 days (IQR 8.0 $62.0)$ at the time of DILI diagnosis. The interval between stopping TBT and initiating a new treatment regimen was 2 days (IQR 0.0 - 7.0).

Exposure to various hepatotoxic drugs (excluding ART) and alcohol was found in 31 (40.8\%) and $13(18.8 \%)$ cases, respectively. None of the patients was serologically positive for hepatitis A virus, whereas 9 (12.3\%) and $3(4.1 \%)$ tested positive for hepatitis B surface antigen and anti-hepatitis $\mathrm{C}$ antibodies, respectively.

The pattern of liver injury most frequently encountered was cholestatic (41.5\%), followed by mixed (39.4\%) and transaminitis (19.1\%).

In total, 53 patients $(56.4 \%)$ were receiving ART, for a median duration of 33.3 days (IQR 20 - 81) before the DILI diagnosis. The most common ART regimen was tenofovir (TDF), lamivudine (3TC) plus efavirenz (EFV) (69.8\%). Patients with ART/TB DILI were similar to those with TB DILI in terms of age, gender, CD4 count at DILI diagnosis, site of TB and pattern of liver injury. More patients with ART/TB DILI than TB DILI presented with symptomatic DILI (71.2\% v. 51.2\%; $p=0.03$ ). Patients with ART/TB DILI had a lower median ALT at DILI diagnosis, with a smaller proportion more than two times the ULN compared with those with TB DILI (89 IU/L v. 118 IU/L; $p=0.008$ and $56.6 \%$ v. $73.2 \%$; $p=0.018$ ). Furthermore, there was a significant difference between the groups for ALT decline between baseline and 4 weeks ( $-76 \mathrm{U} / \mathrm{L}$ v. $-23 \mathrm{IU} / \mathrm{L} ; p=0.047)$, with greater changes observed in the TB DILI group. Patients with ART/TB DILI had been on TBT for longer than those with TB DILI (53 days v. 11 days; $p<0.001)$. The time between stopping TBT and reintroduction of new drugs was also longer in patients with ART/TB DILI (5.0 days v. 1.0 days; $p=0.007)$. More patients with ART/ TB DILI than with TB DILI were reintroduced onto modified TBT $(37.2 \%$ v. $17.1 \% ; p=0.05$, and crude OR 2.17; 95\% CI 0.95 - 4.96).
Patients who were not reintroduced onto either standard or modified treatment regimens because they were lost from care $(17.0 \%)$ were typically older (median age 41.3 years v. 38.9 years), had lower CD4 counts ( $<50$ cells $/ \mu \mathrm{L}$; $50 \%$ v. $38.5 \%)$, had pulmonary TB $(31.3 \% \mathrm{v}$. $16.7 \%)$ and had symptomatic DILI $(81.3 \%$ v. 59.0\%), compared with those who were reintroduced. The rate of death/loss to follow-

up was higher $(10 / 53 ; 18.9 \%)$ among those with ART/TB DILI than among those with TB DILI (6/41, 14.5\%; $p=0.588$ ) (Table 2).

Overall, it took 17.0 days (IQR 14.0 - 72.0) from interrupting TBT to reaching a definitive treatment regimen (standard or modified). In 56 patients $(71.8 \%)$ a standard treatment regimen could be reintroduced, while 22 patients $(28.2 \%)$ required a modified treatment regimen in order

Table 2. Characteristics of patients who achieved standard or modified treatment regimen v. those who were lost from care

\begin{tabular}{|c|c|c|c|}
\hline Characteristics & $\begin{array}{l}\text { Achieved standard or } \\
\text { modified treatment } \\
\text { regimen }(n=78)\end{array}$ & $\begin{array}{l}\text { Lost from care } \\
(n=16)\end{array}$ & $p$-value \\
\hline Gender male, $n(\%)$ & $38(48.7)$ & $7(43.8)$ & 0.717 \\
\hline Age (years), median (IQR) & $38.9(33.7-44.6)$ & $41.3(38.8-51.9)$ & 0.061 \\
\hline ALT at DILI diagnosis, median (IQR) & $109(59-218)$ & $87(57-132)$ & 0.469 \\
\hline TBR at DILI diagnosis, median (IQR) & $48(21-92)$ & $57(39-81)$ & 0.366 \\
\hline Symptomatic DILI, $n(\%)$ & $46(59.0)$ & $13(81.3)$ & 0.105 \\
\hline CD4 count (cells/ $\mu \mathrm{L})$, median (IQR) & $82(31-162)$ & $49(27-152)$ & 0.302 \\
\hline ART/TB DILI, $n(\%)$ & $43 / 78(55.1)$ & $10 / 16(62.5)$ & 0.588 \\
\hline TB DILI, $n(\%)$ & $35 / 78(44.9)$ & $6 / 16(37.5)$ & \\
\hline DILI during intensive phase of TBT, $n(\%)$ & $68(87.2)$ & $15(93.8)$ & 0.672 \\
\hline DILI after start of TBT (days), median (IQR) & $32(7-62)$ & $29(11-61)$ & 0.992 \\
\hline \multicolumn{4}{|l|}{ Site of TB, $n(\%)$} \\
\hline Pulmonary & $13(16.7)$ & $5(31.3)$ & 0.178 \\
\hline Extrapulmonary & $65(83.3)$ & $11(68.8)$ & \\
\hline Concomitant medications, $n(\%)$ & $24(30.8)$ & $6(37.5)$ & 0.727 \\
\hline Pattern of liver injury - mixed, $n(\%)$ & $14(18.0)$ & $4(25.0)$ & 0.804 \\
\hline
\end{tabular}

Table 3. Factors associated with reintroduction onto modified TBT

\begin{tabular}{|c|c|c|c|}
\hline Characteristics & $\begin{array}{l}\text { Proportion with } \\
\text { outcome, } n(\%)\end{array}$ & $\begin{array}{l}\text { Crude OR } \\
(95 \% \mathrm{CI})\end{array}$ & $\begin{array}{l}\text { Adjusted OR } \\
(95 \% \mathrm{CI})\end{array}$ \\
\hline \multicolumn{4}{|l|}{ DILI diagnosis } \\
\hline TB DILI & $6 / 22(27.3)$ & 1 & 1 \\
\hline ART/TB DILI & $16 / 22(72.3)$ & $2.17(0.95-4.96)$ & $1.52(0.76-3.09)$ \\
\hline \multicolumn{4}{|l|}{ Gender } \\
\hline Male & $9 / 22(40.9)$ & 1 & 1 \\
\hline Female & $13 / 22(59.1)$ & $1.37(0.66-2.83)$ & $0.88(0.52-1.51)$ \\
\hline \multicolumn{4}{|l|}{ Age (years) } \\
\hline$\leq 50$ & $18 / 22(81.8)$ & 1 & 1 \\
\hline$>50$ & $4 / 22(18.2)$ & $1.94(0.87-4.32)$ & $1.65(0.62-4.42)$ \\
\hline \multicolumn{4}{|l|}{ Symptomatic DILI } \\
\hline No & $6 / 22(27.3)$ & 1 & 1 \\
\hline Yes & $16 / 22(72.7)$ & $1.57(0.70-3.51)$ & $1.03(0.54-1.95)$ \\
\hline \multicolumn{4}{|l|}{ CD4 count (cells $/ \mu \mathrm{L})$} \\
\hline$>100$ & $9 / 22(40.9)$ & 1 & 1 \\
\hline$<100$ & $13 / 22(59.1)$ & $0.85(0.42-1.75)$ & $0.98(0.57-1.69)$ \\
\hline \multicolumn{4}{|l|}{ Site of TB } \\
\hline Pulmonary & $6 / 22(27.3)$ & 1 & 1 \\
\hline Extrapulmonary & $16 / 22(72.7)$ & $0.53(0.26-1.10)$ & $0.77(0.39-1.53)$ \\
\hline
\end{tabular}


to continue TB therapy. We report the association between ART/TB DILI v. TB DILI (OR 1.52; 95\% CI 0.76 - 3.09) with being reintroduced on a modified treatment regimen, adjusted by age, gender, symptomatic DILI, CD4 count at DILI diagnosis and site of TB. The ORs for symptomatic DILI and age $>50$ years were 1.03 (95\% CI $0.54-1.95)$ and 1.65 (95\% CI 0.62 - 4.42), respectively, while female gender $(0.88$; 95\% CI 0.52 - 1.51$)$ and extrapulmonary TB $(0.77 ; 95 \%$ CI 0.39 - 1.53$)$ appeared protective (Table 3$)$.

Patients reintroduced on a modified treatment regimen had a lower baseline median ALT (89.0 IU/L, IQR 55.0 - 202.0) than those introduced on a standard treatment regimen (118 IU/L, IQR 74.5 $241.0 ; p=0.030$ ). The rate of decline of ALT and TBR 4 weeks after DILI diagnosis was slower in patients reintroduced on a modified treatment regimen $(16.0 \%$ v. $46.0 \% ; p=0.03)$ than in those reintroduced on a standard regimen $(72.0 \%$ v. $63.0 \% ; p=0.04)$.

\section{Discussion}

In this retrospective study we describe patient characteristics and final treatment regimen of $94 \mathrm{~TB} / \mathrm{HIV}$ co-infected patients presenting with TB DILI at a hospital-based TB clinic. Previous studies have suggested that age $>35$ years, hypoalbuminaemia and female gender are risk factors for TB DILI. ${ }^{[10]}$ This study suggests that age $>35$ years and hypoalbuminaemia are possible risk factors.

In $71.8 \%$ of TB DILI cases, a standard TBT regimen containing RIF and INH could be reintroduced. According to our study, higher ALT and shorter duration of symptoms at TB DILI diagnosis were associated with successful reintroduction of a standard TBT regimen. The association between higher ALT and successful reintroduction of a standard treatment regimen is unexpected; it may represent true hepatoxicity to PZA, which is reversible with drug cessation, or it may represent transient elevations of liver enzymes or unrelated liver injury as opposed to true TB DILI. Conversely, factors associated with a modified treatment regimen include ART, male gender, symptomatic DILI and age $>50$ years - although these did not achieve statistical significance.

In this study, more than half of the TB DILI patients were exposed to ART. Differentiating between TB DILI, ART-induced DILI and immune reconstitution inflammatory syndrome (IRIS) is challenging. ${ }^{[10-12]}$ When comparing TB DILI patients on ART v. not on ART, we observed some interesting differences. Patients on ART tended to have a significantly longer duration of TBT at DILI diagnosis, lower ALT at DILI diagnosis, longer treatment interruption until rechallenge of TBT, smaller serial changes in ALT, and higher odds of receiving a modified TBT regimen. The differential diagnosis for these patients includes TB DILI, ART DILI, TB IRIS, viral hepatitis, other hepatotoxins, sepsis and chronic liver conditions. A definitive diagnosis for the deranged liver function is difficult to make because it requires a liver biopsy, which is not routinely performed. According to this study, healthcare workers seem to be more cautious with reintroducing TBT, especially PZA, in this ART patient group. Rechallenge with PZA was previously not recommended, but a recent trial has shown that most patients tolerate it. ${ }^{[13]}$ Unfortunately we did not capture data on interruption or modification of ART. However, the majority of patients $(69.8 \%)$ in this study were receiving a regimen (TDF/3TC/EFV) considered to pose low risk for the development of hepatotoxicity. ${ }^{[14]}$

\section{Study limitations}

The quality of data captured was dependent on information entered into the medical record. There were some instances where documentation was incomplete, most notably for exposure to other potentially hepatotoxic substances. A small sample size that reached the modified treatment regimen $(n=22)$ may have limited our ability to estimate outcomes in this group accurately, so we interpret these results with caution and recommend a larger sample size and longer follow-up. We have limited data on LFTs before starting TBT, as these are not routinely done in SA. Furthermore, patients who died or were lost to follow-up were excluded from the analysis because they could not be reintroduced onto a standard or modified regimen. This may have introduced selection bias. However, there were no differences in the baseline characteristics of patients who died or defaulted as opposed to those who reached the study-defined endpoint (Table 2).

\section{Conclusions}

Owing to the lack of evidence to compare the efficacy of various reintroduction guidelines, the management of TB DILI remains a controversial topic that lacks a prevailing global consensus. ${ }^{[13]}$ Most guidelines are based on expert opinion. ${ }^{[10-12]}$ In 2013, the South African HIV Clinicians Society published a consensus statement on the management of TB DILI in HIV-infected individuals. ${ }^{[15]}$ The consensus statement provides healthcare workers with practical guidance on reintroducing TBT and ART.

There is an important need for future studies to further investigate the underlying mechanism of TB DILI. The ability to differentiate true TB DILI from other hepatic insults will allow for more accurate diagnosis and appropriate management. IRIS, HIV-related opportunistic infections, and other hepatotoxins (e.g. alcohol and prescription and traditional medicines) are common in our setting and may masquerade as TB DILI. Patient education and counselling are simple yet important steps that can be taken to reduce the impact of TB DILI.

We have demonstrated that a significant proportion of patients will require modified TBT. These patients are likely to be males aged $>50$ years who are on ART and present with symptomatic DILI. There also appears to be an association between ART and more severe DILI.

Funding. DE and RB's funding was provided by the US Agency for International Development (USAID) under the terms of agreement USAID674-A-12-00029. This study was made possible by the generous support of the American people through Cooperative Agreement AID 674-A-12-00029 from USAID. The contents of the article are the responsibility of the authors and do not necessarily reflect the views of USAID, the National Institutes of Health or the US government. Right to Care provided some funding for technical and logistic support and for the provision of treatment for patients in this study.

\section{References}

1. World Health Organization. Tuberculosis fact sheet No. 104, March 2012. www.who.int/mediacentre/ factsheets/fs104/en/ (accessed 27 April 2012).

2. World Health Organization. Tuberculosis global facts 2011/2012. www.who.int/entity/tb/ publications/2011/factsheet_tb_2011.pdf (accessed 27 April 2012).

Baddeley A, Dias HM, Falzon D, et al. Global Tuberculosis Control: WHO Report 2011. Geneva: World Health Organization, 2011.

Schaberg T. The dark side of antituberculosis therapy: Adverse events involving liver function. Eur Respir J 1995;8(8):1247-1249. [http://dx.doi.org/10.1183/09031936.95.08081247]

Respir J 1995;8(8):1247-1249. [http://dx.doi.org/10.1183/09031936.95.08081247]
Tostmann A, Boeree MJ, Aarnoutse RE, et al. Antituberculosis drug-induced hepatotoxicity: Concise up-todate review. J Gastroenterol Hepatol 2008;23(2):192-202. [http://dx.doi.org/10.1111/j.1440-1746.2007.05207.x] 6. Shang P, Xia Y, Liu F, et al. Incidence, clinical features and impact on anti-tuberculosis treatment of anti-tuberculosis drug induced liver injury (ATLI) in China. PLoS One 2011;6(7):e21836. [http:// dx.doi.org/10.1371/journal.pone.0021836]

7. Yee D, Valiquette C, Pelletier M, et al. Incidence of serious side effects from first-line antituberculosis drugs among patients treated for active tuberculosis. Am J Respir Crit Care Med 2003;167(11):14721477. [http://dx.doi.org/10.1164/rccm.200206-626OC]

8. Hassen AA, Belachew T, Yami A, et al. Anti-tuberculosis drug induced hepatotoxicity among TB/ HIV co-infected patients at Jimma University hospital, Ethiopia: Nested case-control study. PLoS One 2013;8(5):e64622. [http://dx.doi.org/10.1371/journal.pone.0064622]

9. Schutz C, Ismail Z, Proxenos CJ, et al. Burden of antituberculosis and antiretroviral drug-induced liver 9. Schutz C, Ismail Z, Proxenos CJ, et al. Burden of antituberculosis and antiretrovir
injury at a secondary hospital in South Africa. S Afr Med J 2012;102(6):506-511.

10. Saukkonen JJ, Cohn DL, Jasmer RM, et al. An Official ATS Statement: Hepatotoxicity of antituberculosis therapy. Am J Respir Crit Care Med 2006;174(8):935-952. [http://dx.doi.org/10.1164/rccm.200510-1666ST] therapy. Am J Respir Crit Care Med 2006;174(8):935-952. [http://dx.doi.org/10.1164/rccm.200510-1666ST] force of the European Respiratory Society (ERS), the World Health Organization (WHO), and the International Union against Tuberculosis and Lung Disease (IUATLD) Europe Region. Eur Respir 1999;14(4);978-992. [http://dx.doi.org/10.1183/09031936.99.14497899]

12. Joint Tuberculosis Committee of the British Thoracic Society. Chemotherapy and management of tuberculosis in the United Kingdom: Recommendations of the Joint Tuberculosis Committee of the British Thoracic Society. Thorax 1998;53(7):536-548. [http://dx.doi.org/10.1136/thx.53.7.536]

3. Sharma SK, Singla R, Sarda P, et al. Safety of 3 different reintroduction regimens of antituberculosis drugs after development of antituberculosis treatment-induced hepatotoxicity. Clin Infect Dis 2010;50(6):833-839. [http://dx.doi.org/10.1086/650576]

14. Nunez M. Hepatotoxicity of antiretrovirals: Incidence, mechanisms and management. J Hepatol 2006;44(1 Suppl):S132-S139. [http://dx.doi.org/10.1016/j.jhep.2005.11.027]

15. Jong E, Conradie F, Berhanu R, et al. Consensus statement: Management of drug-induced liver injury in HIVpositive patients treated for TB. S Afr J HIV Med 2013;14(3):113-119. [http://dx.doi.org/10.7196/sajhivmed.976] Accepted 18 March 2015. 